\title{
Erratum to: Radiation-induced bystander effects in the Atlantic salmon (salmo salar L.) following mixed exposure to copper and aluminum combined with low-dose gamma radiation
}

\author{
Carmel Mothersill • Richard W. Smith • Lene Sørlie Heier • \\ Hans-Christian Teien - Ole Christian Lind - Colin B. Seymour • \\ Deborah Oughton • Brit Salbu
}

Published online: 13 February 2014

(C) Springer-Verlag Berlin Heidelberg 2014

\section{Erratum to: Radiat Environ Biophys \\ DOI 10.1007/s00411-013-0505-6}

The author would like to correct the errors in the publication of the original article. The corrected details are given below for your reading:

One of the co-authors' (Ole Christian Lind) family name has been published incorrectly. The correct complete name should be Ole Christian Lind.
The affiliation of the following authors C. Mothersill, L. S. Heier, H.-C. Teien, O. C. Lind, C. B. Seymour, D. Oughton and B. Salbu is incorrect. The correct affiliation is:

Centre for Environmental Radioactivity (CoE), University of Life Sciences, 1432 Ås, Norway.

The online version of the original article can be found under doi:10.1007/s00411-013-0505-6.

C. Mothersill $(\varangle) \cdot$ R. W. Smith · C. B. Seymour Medical Physics and Applied Radiation Sciences Department, McMaster University, Hamilton, ON L8S 4K1, Canada e-mail: mothers@mcmaster.ca

C. Mothersill · L. S. Heier · H.-C. Teien ·

O. C. Lind · C. B. Seymour · D. Oughton · B. Salbu

Centre for Environmental Radioactivity $(\mathrm{CoE})$,

University of Life Sciences, 1432 Ås, Norway 